Hydrology and Earth System Sciences, 7(5), 744-753 (2003) C $\quad$ EGU

\title{
Dynamical properties of the spatial distribution of snow
}

\author{
Thomas Skaugen ${ }^{1,2}$, Stein Beldring ${ }^{1}$ and Hans-Christian Udnæs ${ }^{1}$ \\ ${ }^{1}$ Norwegian Water Resources and Energy Directorate, P.O. Box 5091, Maj., 0301 Oslo, Norway \\ ${ }^{2}$ Department of Geophysics, University of Oslo, Norway \\ Email for corresponding author: ths@nve.no
}

\begin{abstract}
A simulation exercise has been performed to study the temporal development of snow covered area and the spatial distribution of snow-water equivalent (SWE). Special consideration has been paid to how the properties of the spatial statistical distribution of SWE change as a response to accumulation and ablation events. A distributed rainfall-runoff model at resolution $1 \times 1 \mathrm{~km}^{2}$ has been run with time series of precipitation and temperature fields of the same spatial resolution derived from the atmospheric model HIRLAM. The precipitation fields are disaggregated and the temperature fields are interpolated. Time series of the spatial distribution of snow-water equivalent and snow-covered area for three seasons for a catchment in Norway is generated. The catchment is of size $3085 \mathrm{~km}^{2}$ and two rectangular sub-areas of $484 \mathrm{~km}{ }^{2}$ are located within the larger catchment. The results show that the shape of the spatial distribution of SWE for all three areas changes during winter. The distribution is very skewed at the start of the accumulation season but then the skew decreases and, as the ablation season sets in, the spatial distribution again becomes more skewed with a maximum near the end of the ablation season. For one of the sub-areas, a consistently more skewed distribution of SWE is found, related to higher variability in precipitation. This indicates that observed differences in the spatial distribution of snow between alpine and forested areas can result from differences in the spatial variability of precipitation. The results obtained from the simulation exercise are consistent with modelling the spatial distribution of SWE as summations of a gamma distributed variable.
\end{abstract}

Keywords: Snow, SWE, spatial distribution, simulated hydrometeorological fields

\section{Introduction}

A major cause of flooding in Norway is the combination of intense snowmelt and precipitation. To forecast these events, reliable forecasts of precipitation and temperature are needed and a good estimate of the snow reservoir and its coverage in the catchment at the time of the forecast. The Swedish HBV model (Bergstrøm, 1995; Sælthun, 1996) is used operationally for flood forecasting at the Norwegian water Resources and Energy Directorate (NVE) and has been supplemented with a snow routine developed for use in Norway which accounts for the development of the snow reservoir and the snow coverage at different altitude levels (Killingtveit and Sælthun, 1995). The snow routine assumes that snowfall events are log-normally distributed in space, with a fixed coefficient of variation and perfectly correlated in space. These assumptions imply that the maximum of a new snowfall event will appear, at all times, in exactly the same location as the maximum snowfall from previous snowfall events. Also, the distribution of accumulated snow will have a fixed coefficient of skew and not comply with the principles of the central limit theorem (Feller, 1971, p. 258), which would suggest an increasingly less skewed distribution after accumulations. The ablation process is modelled as uniform over the snow-covered fraction of the catchment.

The shape of the distribution of SWE is important when the snow-covered area (SCA) starts to play a role in the ablation process. When only a fraction of the catchment produces melt water, is the possibility of predicting errors in runoff caused by wrongly estimated SCA increased? The shape of the distribution is central to how the amount of melted snow translates into changes in SCA. If the frequency of small values is small, as would be the case for a normal distribution, the response in SCA to a melting event is small. If, on the other hand, the frequency of small values is high, then significant changes in SCA in response to a melting event can be expected.

From studies of the spatial distribution of daily 
precipitation, a positively skewed distribution has been favoured. The exponential distribution has been a popular choice (Gao and Sorooshian, 1994; Skaugen, 2002), and other studies have indicated that a gamma distribution is suitable (Onof et al., 1998; Mackay et al., 2001). However, studies of the spatial distribution of accumulated SWE in forested areas, often measured at the peak of the accumulation period, show that a normal distribution is often a good model (Marchand and Killingtveit, 1999, 2002; Alfnes et al., 2004). In alpine areas, however, more skewed distributions are found (Marchand and Killingtveit, 2002; Alfnes et al., 2004). Thus, based on the very limited information to hand, an accumulation-ablation model for snow should take into account that single events are positively skewed, whereas accumulated events tend towards a less skewed and even a normal distribution, indicating a process in accordance with the principles of the central limit theorem.

As data on the temporal development of the spatial distribution of SWE is rare and expensive to obtain, a simulation exercise produced time series of spatial distribution of snow for a catchment over three winter seasons. A distributed rainfall-runoff model of resolution $1 \times 1 \mathrm{~km}^{2}$, the Gridded Water Balance model (GWB) (Beldring et al., 2003), which is based largely on the Swedish HBV model, computes the water balance elements for Norwegian conditions with precipitation and temperature as input data. To produce input for the GWB model of appropriate spatial resolution, time series of precipitation and temperature fields generated by the High Resolution Limited Area Model (HIRLAM) have been disaggregated and interpolated respectively. The intention of this study is to produce realistic, spatial fields of snow as time series. Although none of the models used here to produce the spatial fields of SWE is a true representation of the processes, it is, however, assumed that by using a distributed approach, important features of the dynamical properties of the spatial snow distribution are captured.

\section{Methodology}

Different models were used to produce the time series of the spatial distribution of SWE. Obviously, each of the models represents only an approximation to the true process in question. However, as the purpose of this exercise is to study the temporal behaviour of the spatial distribution of SWE, it is assumed that even systematic errors in the models will not disguise the overall features of the dynamical evolution of the snow reservoir. A distributed approach to the estimation of the snow reservoir implies that, in principle, the accumulation and ablation properties of snow at points, are estimated and the collection of points analysed. It is assumed that this procedure limits the effects of the errors associated with the individual models.

\section{THE GRIDDED WATER BALANCE MODEL}

A spatially distributed version of the HBV-model (Bergström, 1995) was used. The model carries out water balance calculations for $1 \mathrm{~km}^{2}$ grid cell elements which are characterised by their altitude and land use. Each grid cell may be divided into two land use zones with different vegetation: a lake area and a glacier area. The model has components for accumulation, subgrid scale distribution and ablation of snow, interception storage, subgrid scale distribution of soil moisture storage, evapotranspiration, groundwater storage and runoff response, lake runoff response and glacier mass balance, and it considers the effects of seasonally varying vegetation characteristics on potential evapotranspiration. The algorithms of the model were described by Sælthun (1996).

The model was run with daily precipitation and air temperature data, using a globally applicable set of model parameters determined by Beldring et al. (2003). The model was calibrated using available information about climate and hydrological processes from gauged catchments in different parts of Norway; parameter values were transferred to other catchments based on a classification of landscape characteristics. The calibration procedure rests on the hypothesis that model elements having common vegetation characteristics, plus land use, pedological, topological and geological conditions controlling their hydrological process dynamics, should be assigned the same parameter values. A multi-criteria calibration strategy was applied, where the residuals between model simulated and observed monthly runoff from 141 catchments located in areas with different runoff regimes and landscape characteristics were considered simultaneously. SWE is computed when temperature is lower than a pre-set threshold value. Snow melt is computed according to a degree-day method, where the melted amount is a function of a degree-day factor and the difference between actual temperature and a pre-set temperature threshold (Sælthun, 1996). The model's capability of simulating the water balance elements (including SWE) is documented in Beldring et al. (2003). Simulated time series of SWE were in good agreement with observed values at a snowpillow located in south central Norway (Vauldalen, 820 m.a.s.l.)

\section{DISAGGREGATION OF PRECIPITATION}

Meteorological and hydrological processes are currently described on different spatial scales. Meteorological 
operational atmospheric models such as the HIRLAM use grid sizes of $11 \times 11 \mathrm{~km}^{2}$ and $50 \times 50 \mathrm{~km}^{2}$ whereas hydrological distributed models, such as the GWB, use $1 \times 1 \mathrm{~km}^{2}$. The problem represented by this discrepancy in spatial scale was addressed in Skaugen (2002), where the spatial rainfall fields are simulated according to a mixture of exponential distributions. This methodology is applied in this study to provide continuous precipitation fields of spatial resolution $1 \times 1 \mathrm{~km}^{2}$. From a rainfall field consisting of grid cells of $11 \times 11 \mathrm{~km}^{2}$, precipitation values for pixels of resolution $1 \times 1 \mathrm{~km}^{2}$ were estimated. From the nodal values of a grid cell, the mean and the standard deviation are estimated and decisions made on whether or not the grid cell is completely covered with precipitation. If the standard deviation is smaller than the mean, this implies a shifted exponential distribution, with a location parameter (minimum value) denoted $b$. If the standard deviation is larger than the mean, it implies that the grid cell is only partially covered with precipitation and the spatial fraction, $p$, of the grid cell with precipitation is estimated according to Skaugen (2002) as $p=2 /\left(\left(\operatorname{var}(z) / E(z)^{2}\right)+1\right)$, where $\operatorname{var}(z)$ and $E(z)$ are the unconditional variance and mean (including zeros) of the grid cell. The disaggregation procedure is carried out according to the following points:

(1) Let each grid cell be subdivided into 121 pixels. For the 121 pixels in each grid cell, each pixel is assigned a value interpolated from the nodal precipitation values (the four corner values) of the grid cell. This procedure is repeated for the $\mathrm{N}$ grid cells. Each pixel in the field is assigned a rank ( 1 to $\mathrm{N}^{*} 121$ ), according to its interpolated value.

(2) For each grid cell, the spatial mean and the spatial variance of the grid cell are estimated from the nodal values of the grid cell.

(3) For each grid cell, the spatial mean and variance is calculated and intermittency, $p$, is estimated by $p=2 /$ $\left(\left(\operatorname{var}(z) / E(z)^{2}\right)+1\right)$, where $z$ is precipitation. Depending on whether $p$ is higher or less or equal to 1 , it is decided if the grid cell is (i) completely covered with a minimum intensity $b$, and exponentially distributed precipitation, $f(z ; \lambda, b),(p>1)$, where $\lambda$ is the parameter of the exponential distribution and $b$ is a location parameter, or (ii) intermittent with fractional coverage $p$ and positive precipitation is exponentially distributed, $f(z$; $\lambda, b),(p \leq 1)$.

(4) In case of full coverage, 121 values are simulated from $f(z ; \lambda, b)$, and in the case of intermittency, $p 121$ values are simulated from $f(z ; \lambda)$.

(5) Points (2) to (4) are repeated for every grid cell $1, . ., \mathrm{N}$

6) The $N^{*} 121$ simulated values are then ordered and the ranked pixels from (1) are assigned the simulated value of equal order. In case of intermittency, the (1-p) 121 lowest ranked pixels from each grid cell are assigned the value zero.

Figure 1 shows an example of the initial HIRLAM field of grid cells (Fig. 1a), and the disaggregated field (Fig. 1b). The disaggregation procedure respects intermittency, the mean and the spatial correlation structure of the original HIRLAM field, whereas the spatial variance is somewhat higher for the disaggregated field (Skaugen, 2002). The global pixel ranking may provide rather smooth fields. Other downscaling methods that condition downscaled values on observed spatial patterns may resolve local variability better (Salathe Jr, 2003; Mackay et al., 2001). These methods, however, need observed spatial patterns observed at a reasonable spatial resolution, which is not to hand for this study.

\section{INTERPOLATION OF TEMPERATURE}

Daily temperature values for the model grid cells were determined by inverse distance interpolation of data from the two closest HIRLAM grid cells. Differences caused by elevation were corrected by fixed temperature lapse rates equal to -0.47 and $-0.62{ }^{\circ} \mathrm{C}$ per 100 metres for days with and without precipitation, respectively.

\section{Results and discussion}

Time series of daily values of precipitation and temperature, disaggregated and interpolated to $1 \times 1 \mathrm{~km}^{2}$, were estimated from the output of the HIRLAM model for the Gaula catchment for the period 1st October 1999-1st September 2002. Figure 2 shows the location of the Gaula catchment $\left(3085 \mathrm{~km}^{2}\right)$ with the topography and the location of the subareas, each with size $484 \mathrm{~km}^{2}$. The mean altitude of the Gaula catchment is 729 m.a.s.l whereas the northern sub-area has a mean altitude of 585 m.a.s.l and the southern sub-area has a mean altitude of 858 m.a.s.l. Daily values of SWE are calculated for the time period for each grid cell.

Figure 3 shows the cumulative distribution function for SWE (not including zeros) for the three catchments for the start of the accumulation season, the peak of the accumulation season and at the end of the ablation season. Table 1 shows the spatial mean, spatial standard deviation, coefficient of variation (CV) and the coefficient of skew for the same periods of the season. For the Gaula and southern sub-area, the distributions are relatively skewed in the beginning of the season. The skew has decreased at the peak of accumulation and increases significantly at the end of the ablation season. For the northern sub-area, it appears that the skew has increased steadily throughout the 
(a)
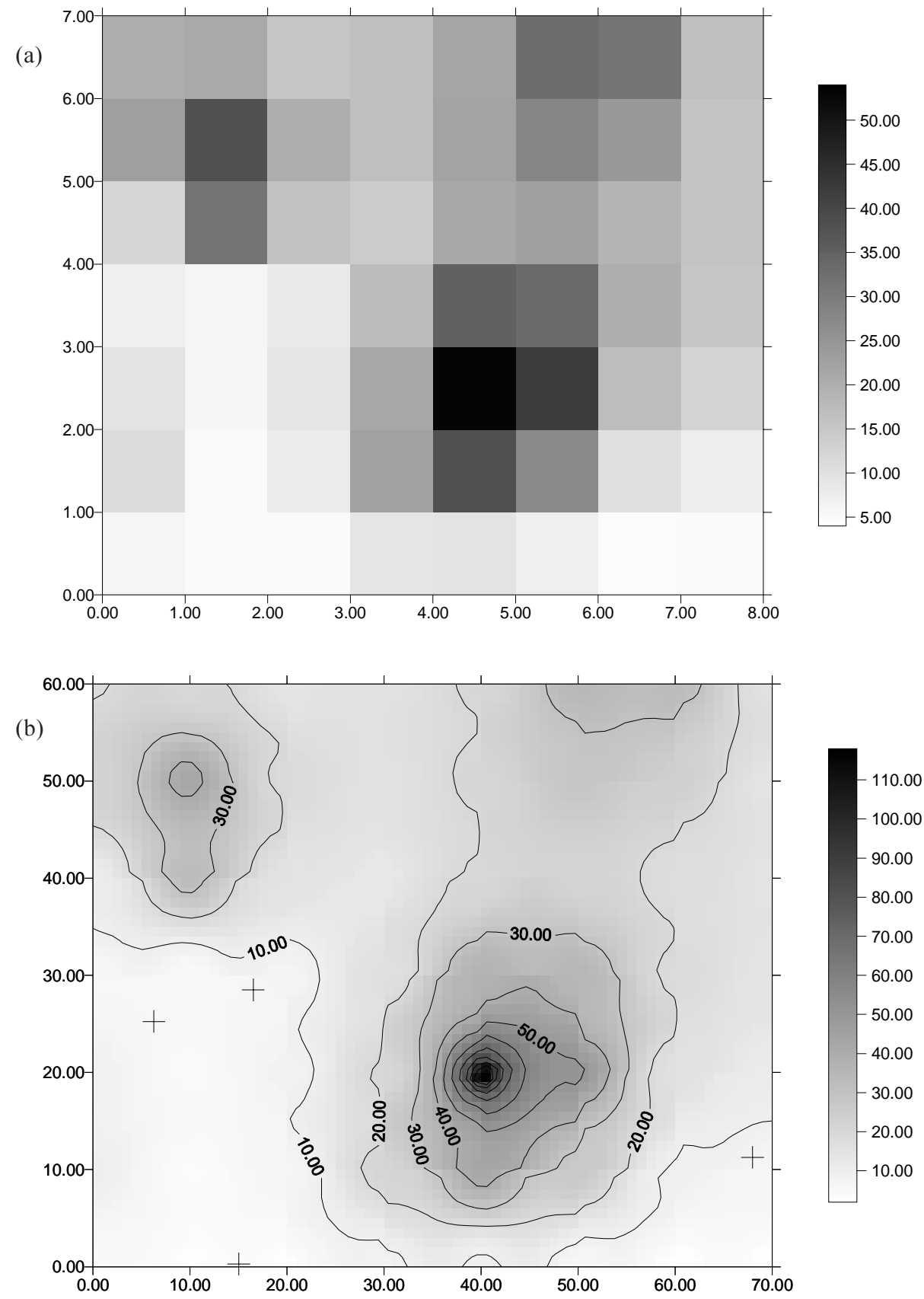

Fig. 1. Hirlam field (a) and disaggregated field (b) of the 6th August 2000. + marks locations of precipitation gauges. The unit is mm day ${ }^{-1}$

season.

Note that the northern sub-area, being situated in the lower region of the Gaula catchment, only received about $60 \%$ of the amount of snow compared to the southern sub-area at the peak of the accumulation season.

A similar pattern of temporal variability in the statistical parameters $\mathrm{CV}$ and skew can be observed in Fig. 4, where the $\mathrm{CV}$, skew and SCA for the three areas are plotted as time series. The coefficient of variation and the skew are obviously correlated; high fluctuations occur at the beginning of the season, then decrease during the accumulation season, before increasing as the melting season sets in. This development is in accordance with the principle of the central limit theorem (Feller, 1971, p.258) which would give a decrease in skew during accumulations, then the ablation process acts as a reverse providing an increasingly more skewed distribution.

An interesting feature of Fig. 4 is that the coefficient of 


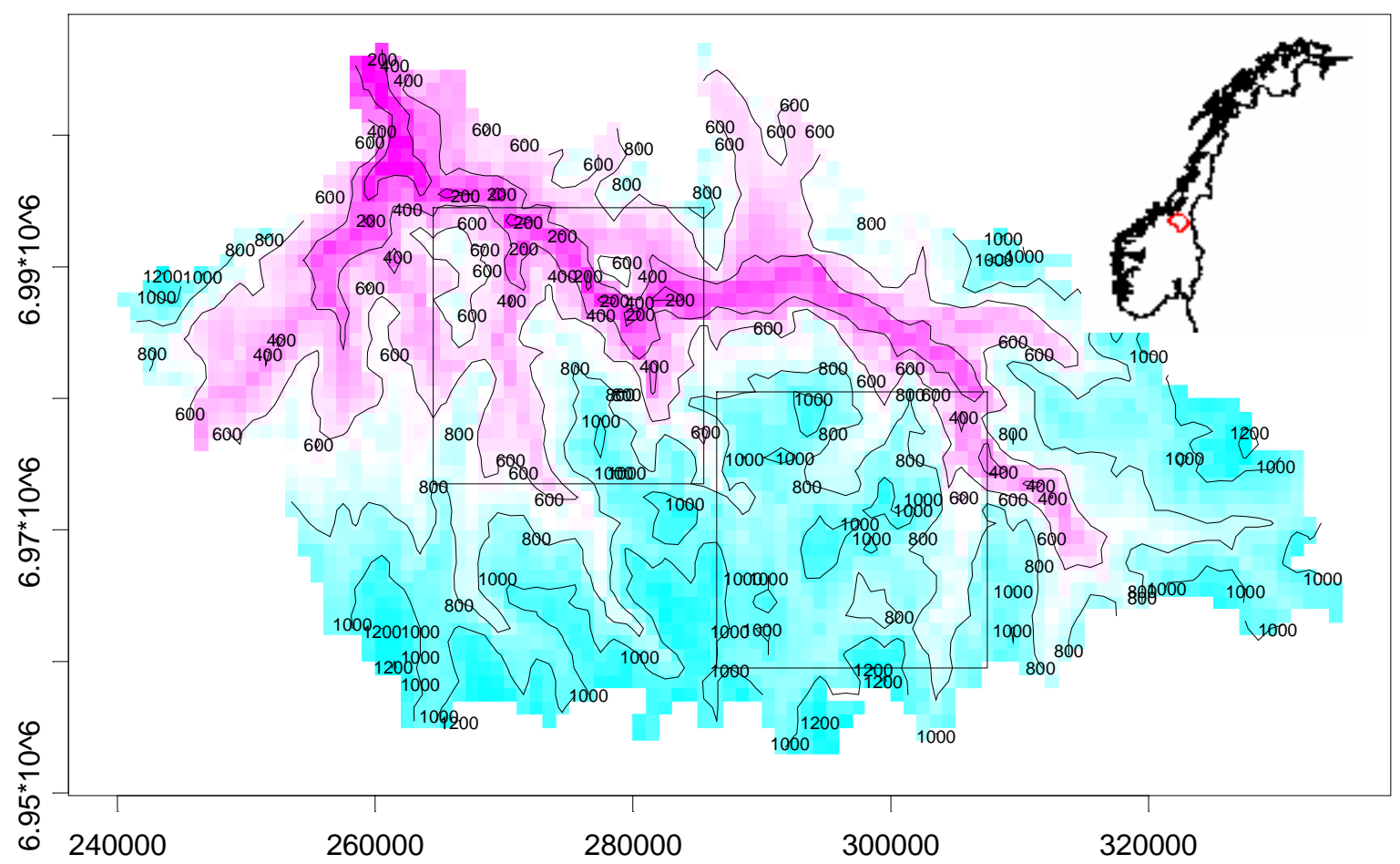

Fig. 2. The topography of the Gaula catchment (m.a.s.l. in metres) with the two sub-areas (coordinate system UTM zone 32). Norway and location of the Gaula catchment (small square) is seen in the upper right corner.

Table 1. Statistical parameters for the spatial distribution of SWE for the start of the accumulation season $\left(8^{\text {th }}\right.$ October 1999$)$ peak of the accumulation season $\left(14^{\text {th }}\right.$ April 2000$)$ and end of the ablation season (18 ${ }^{\text {th }}$ August 2000)

\begin{tabular}{lllcc}
\hline Catchment & Date & 8th October & 14th April & 18th August \\
\hline \multirow{2}{*}{ Gaula } & Mean (mm) & 3.5 & 579.5 & 97.3 \\
& Std.dev. (mm) & 4.7 & 369.9 & 173.9 \\
& CV & 1.34 & 0.63 & 1.78 \\
Northern Sub-area & Skew & 1.12 & 0.88 & 1.55 \\
& Mean (mm) & 1.3 & 383.6 & 3.22 \\
& Std.dev. $(\mathrm{mm})$ & 1.5 & 114.5 & 3.2 \\
Southern Sub-area & CV & 1.15 & 0.30 & 0.99 \\
& Skew & 1.13 & 0.49 & 1.09 \\
& Mean (mm) & 5.5 & 661.8 & 55.25 \\
& Std.dev. (mm) & 4.7 & 315.5 & 102.1 \\
& CV & 0.85 & 0.48 & 1.85 \\
& Skew & 0.76 & 0.93 & 1.45 \\
\hline
\end{tabular}

skew is consistently much higher for the southern sub-area than for the northern sub-area. It is commonly observed that the distribution of snow courses in alpine areas (above the timber line) tend to be more skewed than those in forested areas (Alfnes et al., 2004; Marchand and Killingtveit, 2002). There have been many attempts to link the spatial distribution of SWE to physical parameters such as elevation, slope, aspect, net solar radiation and the type and density of vegetation cover (Erxleben et al., 2002; Elder et al., 1989). However, large portions of the observed variability in the snow depth remain unexplained. Redistribution due to wind has also been a popular descriptor, but more difficult to verify, although at sufficiently small spatial scales, redistribution caused by 

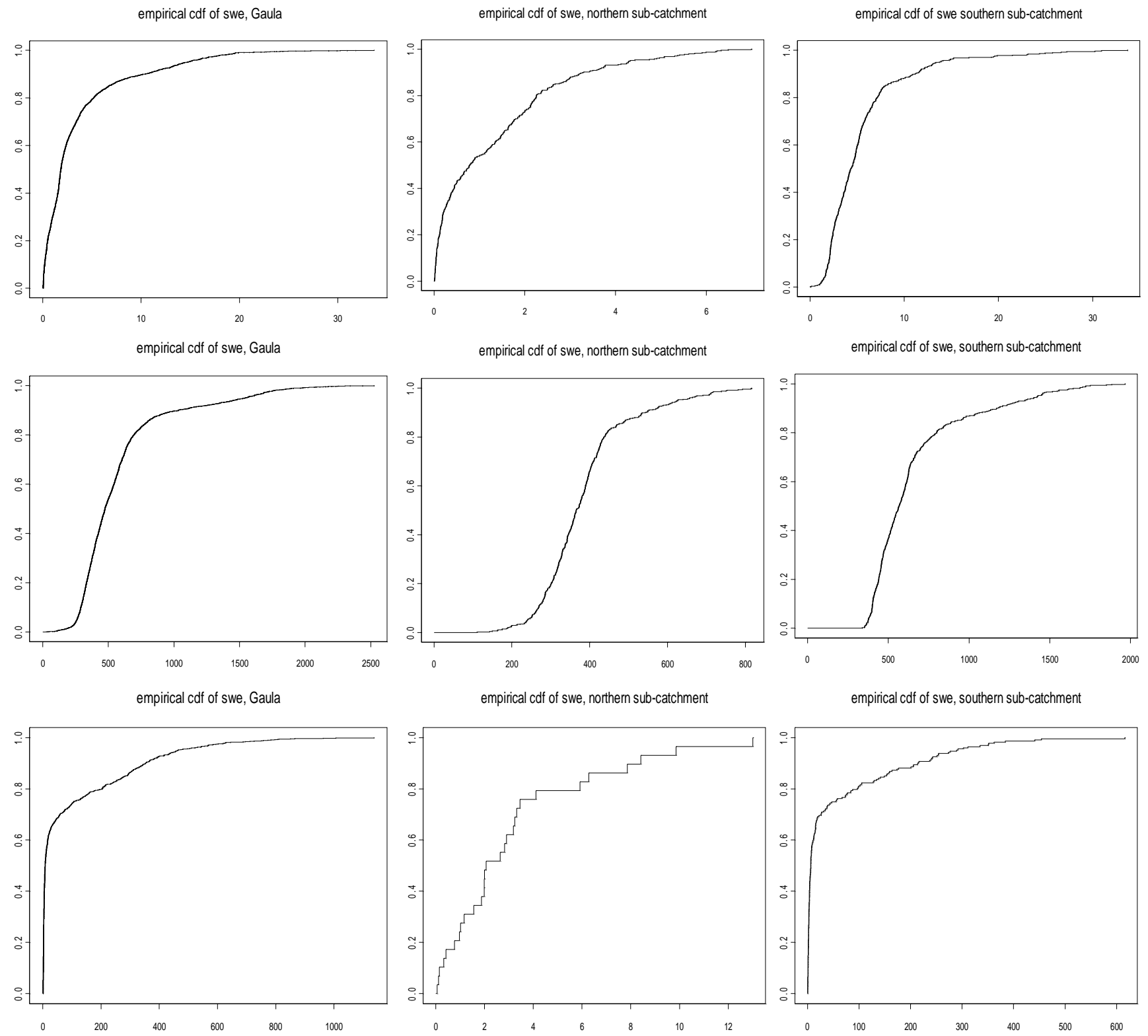

Fig. 3. Cumulative distribution functions of the spatial distribution of SWE for the Gaula catchment (left column), northern sub-area (middle column) and southern sub-area (right column) for the start of the accumulation season (top row), peak of accumulation season (middle row) and end of the ablation season (bottom row).

wind is certainly an issue. These unsuccessful attempts to link distribution of SWE to physical parameters may be explained by a mismatch in spatial scales between predictor and descriptors which, as pointed out by Blöschl (1999), may seriously affect predictions. This important point is valid when there is a mismatch in process scales, but will also play a role when the spacing and extent of observations do not capture the variability of the processes involved. In this study, features of the spatial distribution of SWE were not explicitly linked to such physical parameters as described above, and all features observed of the spatial distribution of SWE, at least in the accumulation season, stem from the effects of accumulating disaggregated precipitation fields.

From Fig. 5, which shows the temporal development of the spatial mean and the spatial standard deviation for the three catchments, it can be observed that for similar values of the spatial mean for the three areas, the spatial variability is considerably less for the northern sub-area, thus having the smallest $\mathrm{CV}$ during the accumulation season. The daily spatial $(\log )$ variability of precipitation from the grid cells $(3 \times 3)$ covering the each of the two sub-areas are sorted and plotted, as shown in Fig. 6. Observe that the spatial 
Thomas Skaugen, Stein Beldring and Hans-Christian Udnæs
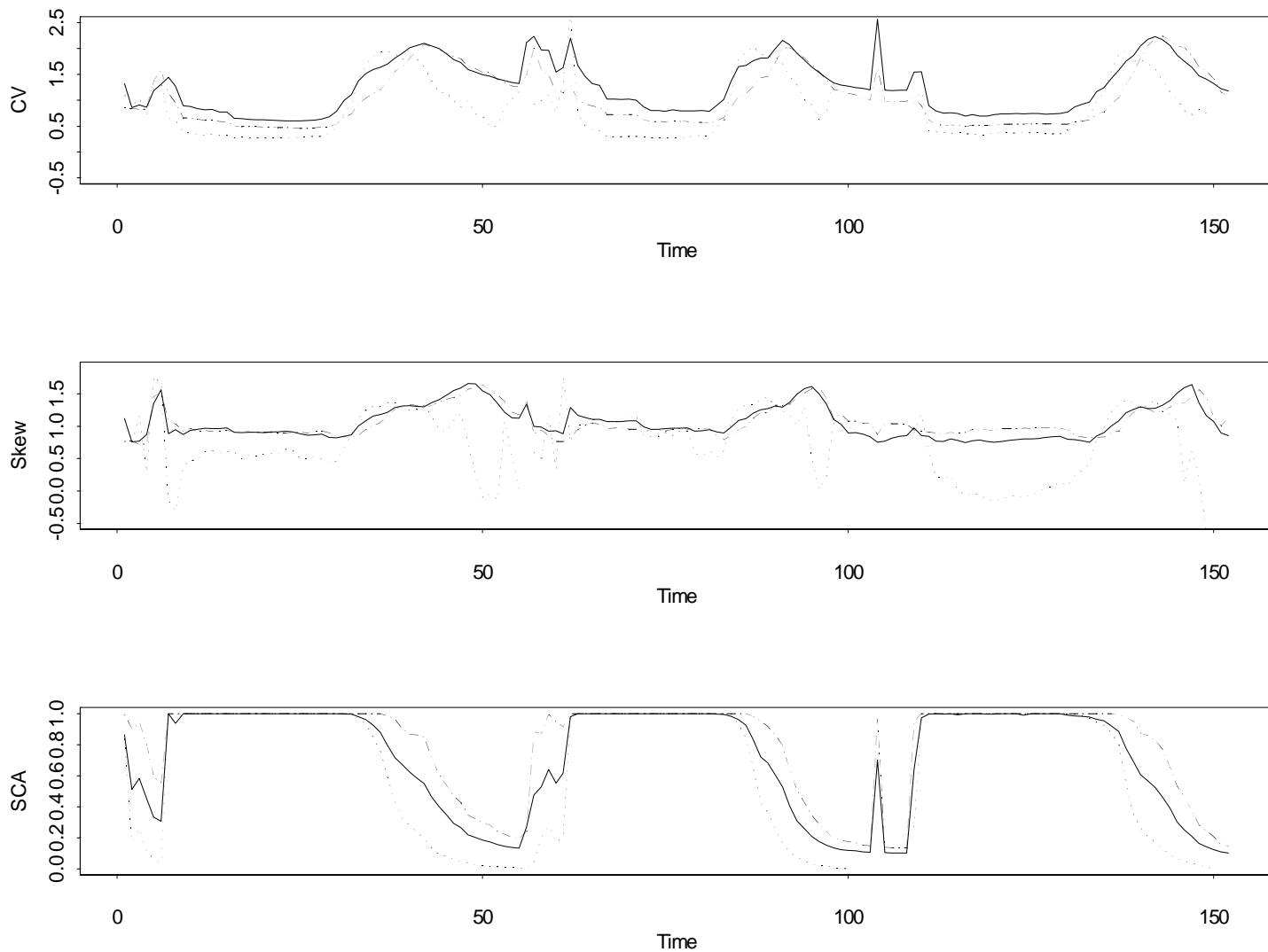

Fig. 4. Time series of the CV and Skew for the spatial distributions of SWE and SCA, for the Gaula catchment (solid line), northern sub area (dotted line) and southern sub area (dashed line). The label "Time" refers to week numbers starting from the beginning of the first accumulation season.
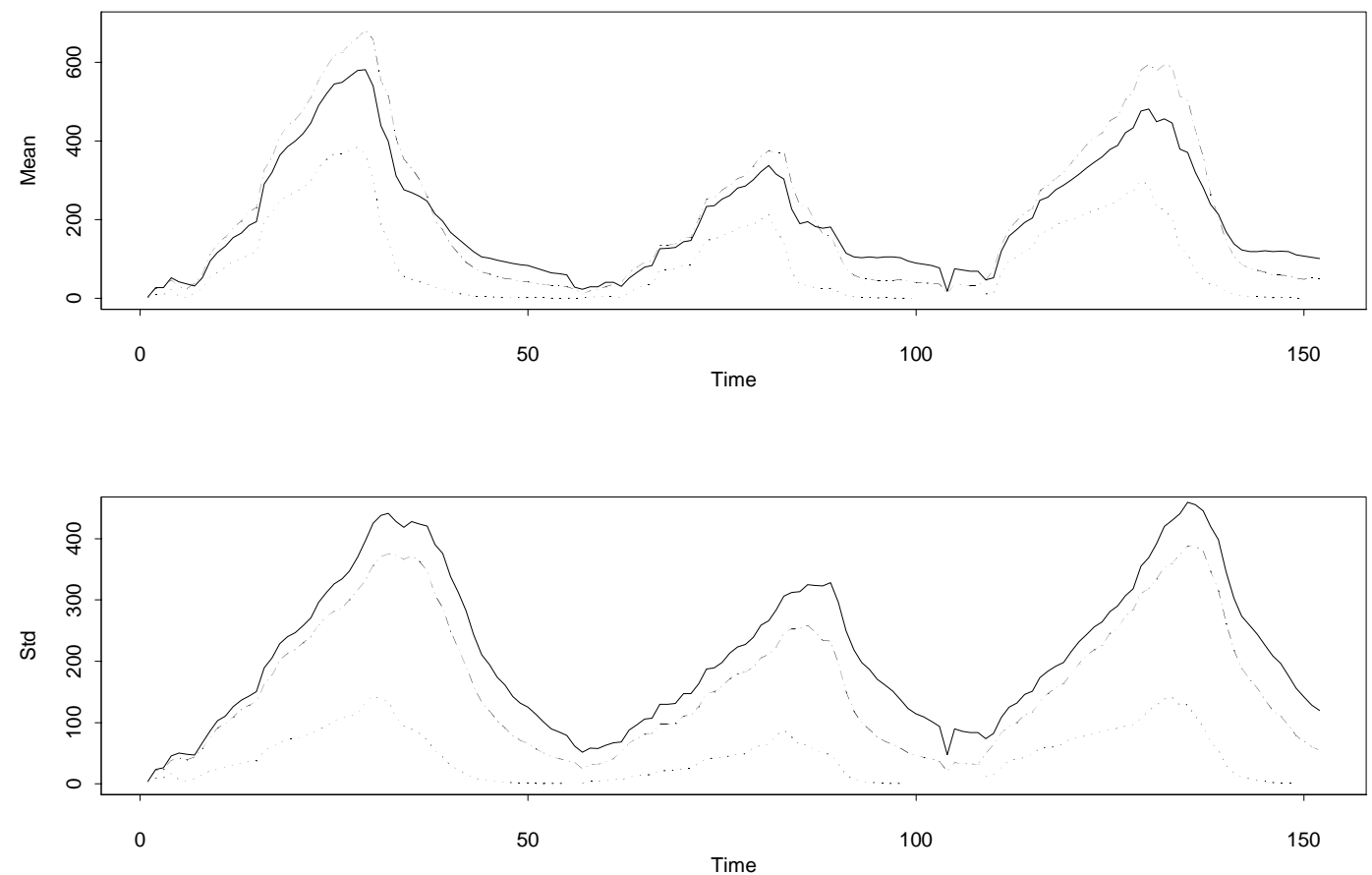

Fig. 5. Time series of the mean and standard deviation for the spatial distributions of SWE, for the Gaula catchment (solid line), northern subarea (dotted line) and southern sub-area (dashed line). The label "Time" refers to week numbers starting from the beginning of the first accumulation season. 


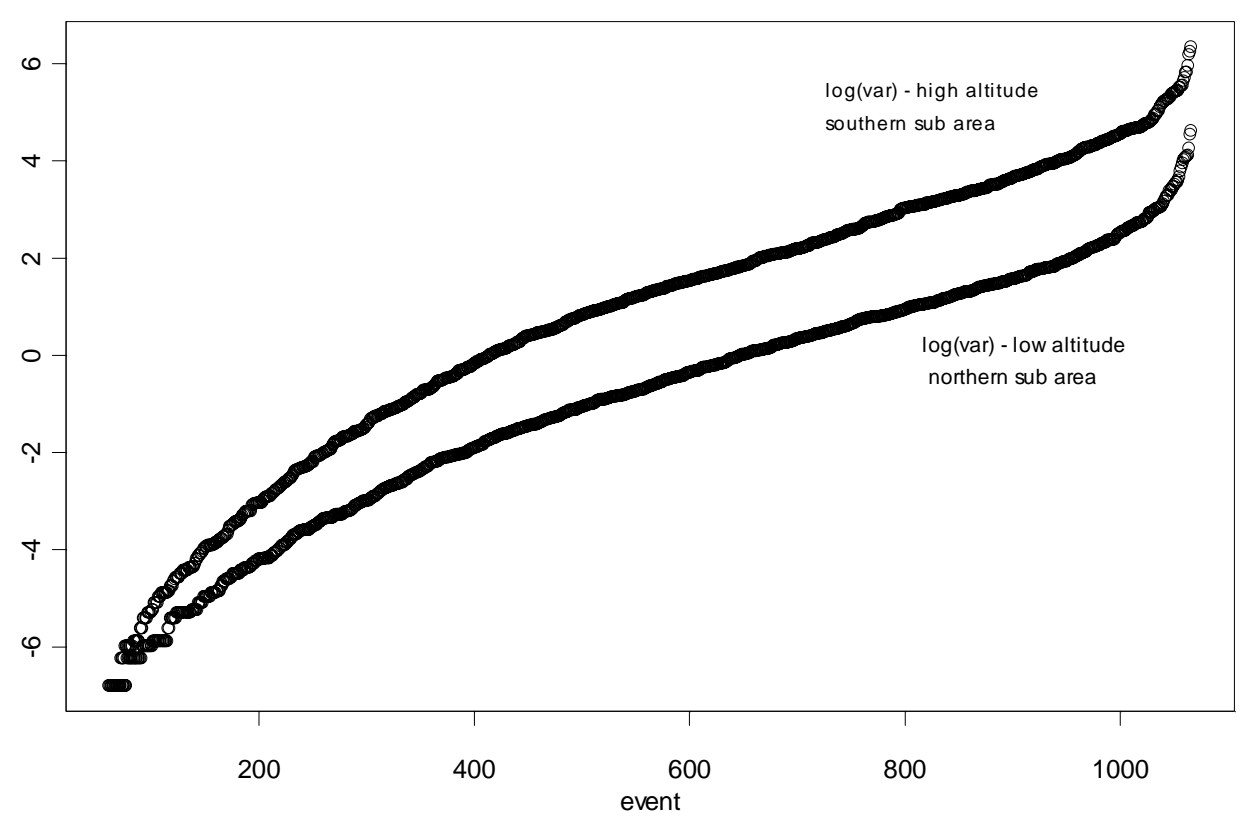

Fig. 6. Spatial daily (log) variability for the northern and southern sub-areas. Daily spatial variability is calculated for $3 X 3$ grid cells covering the respective sub-areas and sorted.

variability of daily events for the high altitude sub-area is consistently higher than for the low altitude sub-area, thus explaining the increased CV for the high altitude sub area. Figure 5 further shows that the coefficient of skew and the CV appear to be correlated. Several popular choices for the distribution of SWE, like the lognormal and gamma distribution (Sælthun and Killingtveit, 1995; Skaugen, 1999; Skaugen et al., 2004), have theoretical expressions of the coefficient of skew being an unambiguous function of the CV. It thus appears that the skewed spatial distribution of SWE found in alpine areas can be explained partly by the increased spatial variability of precipitation in such areas.

Only in a very few cases can the distribution of accumulated events be described analytically. Spatial independence and independence between events are typical constraints. Also, seen from a spatial point of view, the events should be identically distributed. Both the normal and the gamma distribution have analytical expressions for the distribution of the accumulations. Analytically, these models break down for precipitation fields of varying spatial distributions which are correlated in space and time. Despite these theoretical problems, Skaugen et al., (2004) proposed a statistical model that takes account of the dynamic behaviour of the spatial distribution of SWE. In Skaugen (1999), the distribution of accumulated snow was modelled as a summation of independent, identically distributed gamma variables. This modelling framework allows positively skewed gamma distributed single events, whereas the distribution of the accumulated events will also be gamma distributed but with parameters determined by the original gamma distribution and the number of accumulations. The distribution of the accumulated events will converge to a normal with a rate depending on the parameters of the gamma distribution and the number of accumulations. This approach was carried further in Skaugen et al., (2004), where a gamma distributed unit SWE was introduced. An event of accumulation or ablation, which may comprise a number of units will, under an assumption of independence, also be gamma distributed. This modelling framework was implemented within the HBV model, and a routine for modelling the temporal development of the snowcovered area was developed, linking the change in SCA as a response to an accumulation or ablation event directly to the parameters of the spatial distribution of SWE. The main features of the accumulation-ablation model of Skaugen et al., (2004) are described as follows: Let $y$ be a SWE equivalent and a gamma distributed random variable with probability density function (PDF):

$$
f_{\alpha, v}(y)=\frac{1}{\Gamma(v)} \alpha^{v} y^{v-1} e^{-\alpha y} \quad \alpha, v, y>0
$$

where $\alpha$ is the scale parameter and $v$ is the shape parameter. The mean equals $E(y)=v / \alpha^{2}$ and the variance equals $\operatorname{Var}(y)$ $=v / \alpha^{2}$. If the variable $y_{i}$ is approximated to be an independent and identically distributed gamma variable in time and space, then $z t(x)=y_{1}+y_{2}+. .+y_{n}$ is distributed as a gamma variable with parameters $\alpha$ and $n v$ (Feller, 1971, p.47). The parameters $\alpha$ and $v$ are catchment-specific parameters determined by the local climate, whereas the 
parameter $n$ represents the accumulated number of SWE equivalents in the snow reservoir at a certain time of interest. Thus, the spatial distribution of accumulated SWE, $z$, at a given time has mean and variance equal to:

$$
\mathrm{E}(\mathrm{z})=\mathrm{n} v / \alpha
$$

and

$$
\operatorname{Var}(\mathrm{z})=\mathrm{n} v / \alpha^{2}
$$

When implemented in the HBV model, $y$ is allowed to fluctuate around its mean for each accumulation or ablation event, so that $y=u v / \alpha$, where $u$ is gamma distributed with mean, $E(u)=1$ and $\operatorname{Var}(u)=1 / \mathrm{v}$. When running the model, $u$ and $n$ are monitored and $n$ updated as $n_{t+1}=n_{t}+u_{t}$ for an accumulation event and $n_{t+1}=n_{t}-u_{t}$, for a melting event.

The coefficient of variation $\mathrm{CV}$ and the skew, $\gamma$, are found to be dynamical parameters in that they are functions of the parameter $n$ :

$$
C V=1 / \sqrt{n v}
$$

and the skew is:

$$
\gamma=2 / \sqrt{n v}
$$

or, when $n v$ is substituted by $E(z) \alpha$ (see Eqn. (2)):

$$
\gamma=2 / \sqrt{(E(z) \alpha}
$$

It is clear from Eqns. (4), (5) and (6) that the value of the $\mathrm{CV}$ and $\gamma$ should decrease during the accumulation season when $n$ grows, and increase in the ablation season when $n$ decreases, in a manner similar to that demonstrated by the simulation exercise. Figure 7 compares simulated values of skew with theoretical values according to Eqn. (6) for the two sub-areas. The values of $\alpha$ used in Eqn. (6) for the two sub-areas are estimated roughly to obtain a reasonable fit. A more accurate estimation of $\alpha$ cannot be made as data for this area are insufficient. Although the skew appears to be highly overestimated by Eqn. (6) for the start and end of the accumulation seasons, Fig. 7 shows that the model does capture the dynamical behaviour of the skew parameter. This is important in order to generate snow-free areas properly in response to melt events and, further, to provide realistic dynamics for the spring flood in hydrological models.

The procedure of modelling the spatial distribution of SWE as a summation of a gamma-distributed variable is approximate in that the assumption of independence in time
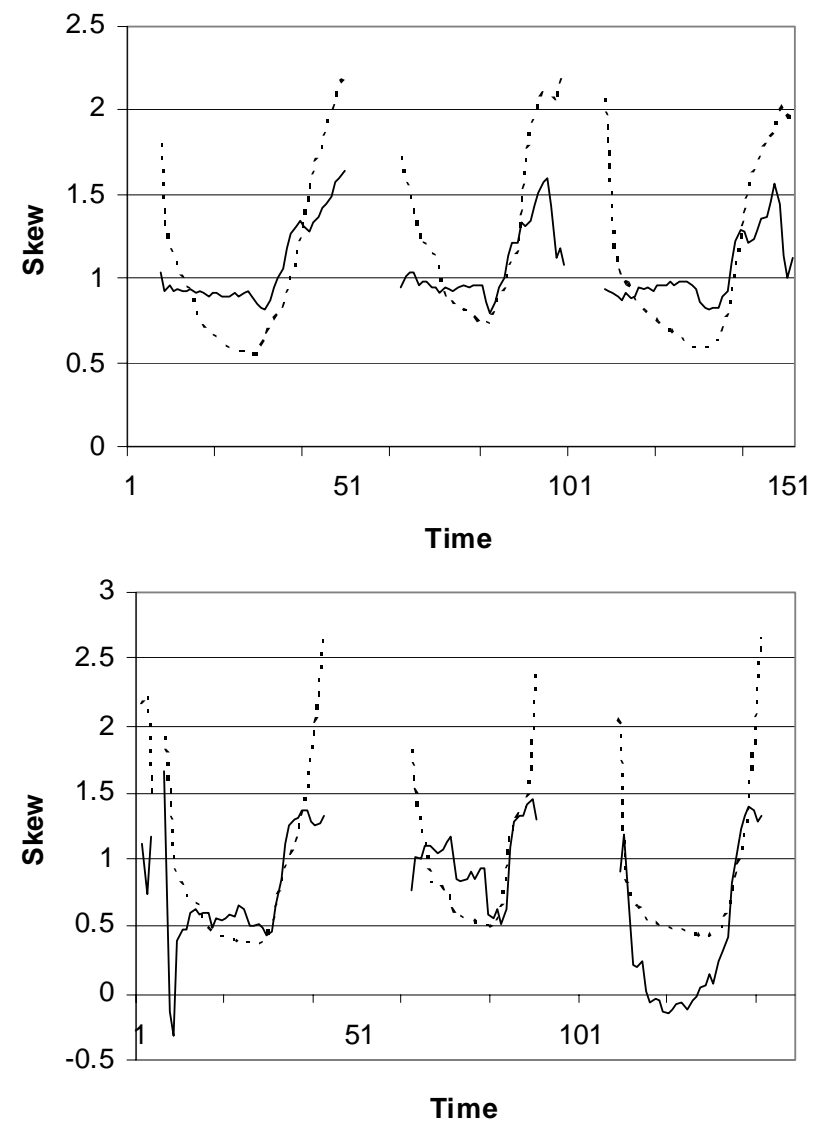

Fig. 7. Temporal development of the skew parameter for simulated SWE (solid line) and by Eqn. (6) (dashed line). Southern sub-area left, and northern sub-area right. Days with less than $6 \mathrm{~mm}$ SWE (northern sub-area) and $40 \mathrm{~mm}$ SWE (southern sub-area) are excluded from the plot.

and space may be compromised to an unknown degree. Regarding the spatial independence, several authors (Elder et al., 1989, Faanes and Kolberg, 1996; Gottschalk and Jutman, 1979) report low autocorrelation for a range of distances. The studies of the latter two references were carried out for Norwegian and Swedish data respectively and are thus representative for the present study. Studies attempting to link snow depth to terrain features have often showed very weak correlations (Elder et al., 1989; Faanes and Kolberg, 1996; Erxleben et al., 2002), so that an assumption of independence in space can be justified. To investigate possible temporal dependencies, Skaugen et al., (2004) reports on data from a snowpillow, Vauldalen (820 m.a.s.1.) located in the central southern Norway, which was tested for autocorrelation. Of the 16 sequences with more than 13 days with snowfall, only 5 had significant autocorrelation for lag 1 day; none of the sequences showed significant autocorrelation for longer time lags. An assumption of temporal independence can thus be justified. 


\section{Conclusions}

Time series of the spatial distribution of SWE have been constructed for three areas at different mean altitudes. All three areas display the same dynamic behaviour in the parameters of the distribution of SWE in that the skew decreases during accumulation season and increases during the ablation season.

The simulation exercise shows that the spatial variability of precipitation could explain a more skewed spatial distribution of SWE in mountainous areas. This may prove important for modelling snow in rainfall-runoff models in that model parameters can be determined from an analysis of the spatial variability of precipitation and not from the calibration process of the rainfall-runoff model. This is a point of departure for further study.

Modelling the spatial distribution of SWE as sums of gamma distributed variables takes into account the dynamic properties of the spatial distribution of SWE in that it allows for a dynamic change in the shape of the distribution in accordance with the simulation exercise, observations and the principles of the central limit theorem.

\section{Acknowledgments}

This study is part of the EnviSnow project supported by the EU under FP5.

\section{References}

Alfnes, E., Andreassen, L.M., Engeset, R.V., Skaugen, T. and Udnæs, H.-C., 2004. Temporal variability in snow distribution. Ann. Glaciol., in press.

Beldring, S., Engeland, K., Roald, L.A., Sælthun, N.R. and Voksø, A., 2003. Estimation of parameters in a distributed precipitationrunoff modell for Norway. Hydrol. Earth Syst. Sci., 7, 304316.

Bergström, S., 1995. The HBV model. In: Computer Models of Watershed Hydrology, V.P. Singh (Ed.). Water Resources Publications, Highlands Ranch, USA. 443-476.

Blöscl, G., 1999. Scaling issues in snow hydrology. Hydrol. Process. 13, 2149-2175.
Elder, K., Dozier, J. and Michaelsen, J., 1989. Spatial and temporal variation of net snow accumulation in a small alpine watershed, Emerald Lake basin, Sierra Nevada, California, USA. Ann. Glaciol., 13, 56-63.

Erxleben, J., Elder, K. and Davis, R., 2002. Comparison of spatial interpolation methods for estimating snow distribution in the Colorado Rocky Mountains. Hydrol. Process. 16, 3627-3649.

Faanes, T. and Kolberg, S., 1996. Optimal utnyttelse av snømagasinet. SINTEF report No. STF22 A96412 (in Norwegian)

Feller, W., 1971. An introduction to probability theory and its applications. John Wiley \& Sons, Ltd., New York, USA. 669pp.

Gao, X. and Sorooshian, S., 1994. A stochastic precipitation disaggregation scheme for GCM applications. J. Clim., 7, 238247.

Gottschalk, L. and Jutman, T., 1979. Statistical analysis of snow survey data. Swedish meteorological and hydrological institute, SMHI, Report No. 20.

Killingtveit, Å. and Sælthun, N-R., 1995. Hydrology. Volume No. 7 in Hydropower Development. NIT, Trondhjem, Norway.

Mackay, N.G., Chandler, R.E., Onof, C. and Wheater, H.S., 2001. Disaggregation of spatial rainfall fields for hydrological modelling. Hydrol. Earth Syst. Sci., 5, 165-173.

Marchand, W-D. and Killingtveit, Å., 1999. Statistical properties of snow cover in mountainous catchments in Norway, Northern Research Basins. Twelfth Internationalymposium and Workshop, Reykjavik, Iceland. 227-239.

Marchand, W-D. and Killingtveit, Å., 2002. Statistical probability distribution of snow on sub-grid cell level. Nordic Hydrological Programme, NHP Report No. 47. 461-471.

Onof, C., Mackay, N.G., Oh, L. and Wheater, H.S., 1998. An improved rainfall disaggregation technique for GCMs. $J$. Geophys. Res., 103, 19577-19586.

Salathé Jr., E.P., 2003. Comparison of various precipitation downscaling methods for the simulation of streamflow in a rainshadow river basin. Int. J. Climatol., 23, 887-901.

Sælthun, N.R., 1996. The Nordic HBV model. Norwegian Water Resources and Energy Administration Publication No. 7, Oslo, 26pp.

Skaugen, T., 1999. Estimating the mean areal snow water equivalent by integration in time and space. Hydrol. Process. 13, 2051-2066.

Skaugen, T., 2002. A spatial disaggregating procedure for precipitation, Hydrol. Sci. J., 47, 943-956.

Skaugen, T., Alfnes, E., Langsholt, E.G. and Udnæs, H.-C., 2004. Time variant snow distribution for use in hydrological models. Ann. Glaciol., in press. 